\title{
Primary Care Provider Understanding of Hair Care Maintenance as a Barrier to Physical Activity in African American Women
}

\author{
Sophia O. Tolliver, MD, MPH, Jennifer L. Hefner, PhD, MPH, \\ Starling D. Tolliver, MS4, and Leon McDougle, MD, MPH
}

Introduction: African American (AA) women have reported hair maintenance as a barrier to regular exercise; however, to our knowledge, this study is the first to identify primary care provider thoughts, attitudes, beliefs, and knowledge regarding hair as a barrier to increased physical activity among AA females.

Methods: A 13-question electronic survey was sent via email to 151 clinicians working within a department of family medicine's 8 ambulatory clinics within a large urban academic medical center.

Results: A total of 62 primary care clinicians completed the survey, which is a response rate of $41 \%$. The vast majority of respondents (95\%) sometimes/often engage in discussions with AA female patients regarding physical activity. However, $76 \%$ of respondents have never included a hairstyling or maintenance assessment in that discussion and only $34 \%$ noted being comfortable discussing this topic. Among a list of potential barriers to exercise, hair maintenance/scalp perspiration was rarely endorsed as important by clinicians.

Discussion: This study highlights a need for increased education among primary care providers regarding AA hair care and maintenance practices as a barrier to increased physical activity in AA women. If specific barriers to increasing healthy habits among AA women are to be addressed, there must be a baseline knowledge of hair care and maintenance barriers, an understanding of the strong influence of cultural norms and practices as it relates to physical activity and exercise, and an increased comfortability when engaging in difficult cross-cultural conversations to ultimately improve health outcomes in AA females. (J Am Board Fam Med 2019;32:944-947.)

Keywords: Cultural Competency, Exercise, Habits, Hair, Health Behavior, Life Style, Minority Health, Obesity, Patient-Centered Care, Primary Health Care, Social Determinants of Health, Surveys and Questionnaires

African American (AA) women have the highest prevalence of obesity and obesity-related conditions, including type 2 diabetes, hypertension, heart disease, and stroke. ${ }^{1}$ Relatedly, this group is less likely than

This article was externally peer reviewed.

Submitted 6 May 2019; revised 16 July 2019; accepted 18 July 2019.

From The Ohio State University Wexner Medical Center Department of Family Medicine, The Ohio State University College of Medicine, Columbus (SOT, JLH, SDT, LM); The Division of Healthcare Management and Policy, College of Public Health, The Ohio State University, Columbus (JLH).

Funding: none.

Conflict of interest: none declared.

Corresponding author: Sophia Tolliver, MD, MPH, The Ohio State University Wexner Medical Center Department of Family Medicine, The Ohio State University College of Medicine, Columbus, OH 43210 (E-mail: sophia.tolliver @osumc.edu). other ethnic groups to participate in physical activity or exercise.,3 A small body of research has identified what AA women perceive to be barriers to increasing and sustaining regular exercise in their lives: cost, time, and hair maintenance. ${ }^{4-7}$ Regarding hair maintenance, in two different surveys of nonexercising AA women, respondents reported "sweating out my hairstyle" as a barrier to exercise. ${ }^{4,8}$ This barrier is related to the time and money required to restyle hair after perspiration. In addition, when AA women seek out help for hair-related issues, a significant number are dissatisfied with hair-related encounters with physicians because AA women did not feel as though their provider understood AA hair.'

A 2013 study proposed that physicians would do well to suggest hairstyles for AA women that would be conducive to increasing physical activity. ${ }^{8}$ In 
Table 1. Responses to a Survey of Primary Care Provider Perceptions of Hair Care Maintenance as a Barrier to Increased Physical Activity in African American Women

\begin{tabular}{|c|c|}
\hline $\begin{array}{l}\text { Question and Response Category } \\
(\text { Total } \mathrm{N}=62 \text { ) }\end{array}$ & Response, N (\%) \\
\hline \multicolumn{2}{|c|}{ Respondent level of training/profession } \\
\hline PGY-1 & $7(12)$ \\
\hline PGY-2 & $7(12)$ \\
\hline PGY-3 & $5(8)$ \\
\hline Attending/faculty & $31(52)$ \\
\hline NP & $10(17)$ \\
\hline \multicolumn{2}{|l|}{ Respondent ethnicity } \\
\hline Caucasian & $40(65)$ \\
\hline Black/African American & $10(16)$ \\
\hline African & $0(0)$ \\
\hline Hispanic/Latino & $0(0)$ \\
\hline Other & $9(14)$ \\
\hline Prefer not to answer & $3(5)$ \\
\hline \multicolumn{2}{|c|}{ Percent of patients who are AA women } \\
\hline $15 \%$ or less & $17(29)$ \\
\hline $16 \%$ to $30 \%$ & $17(29)$ \\
\hline Greater than $30 \%$ & $24(42)$ \\
\hline \multicolumn{2}{|c|}{$\begin{array}{l}\text { How often do you discuss strategies to increase physical } \\
\text { activity/exercise with your AA female patients? }\end{array}$} \\
\hline Never & $1(2)$ \\
\hline Seldom & $2(3)$ \\
\hline Sometimes & $19(30)$ \\
\hline Often & $40(65)$ \\
\hline \multicolumn{2}{|c|}{$\begin{array}{l}\text { How often have you commented on hairstyling and hair } \\
\text { maintenance in your discussion regarding increasing } \\
\text { physical activity/exercise with AA women? }\end{array}$} \\
\hline Never & $47(76)$ \\
\hline Some of the time & $12(19)$ \\
\hline Most of the time & $3(5)$ \\
\hline All of the time & $0(0)$ \\
\hline \multicolumn{2}{|c|}{$\begin{array}{l}\text { Which of the following are moderate or major barriers } \\
\text { between AA women and the pursuit to increase activity/ } \\
\text { exercise? }\end{array}$} \\
\hline & $\begin{array}{l}\text { Moderate/Major } \\
\text { Barrier }\end{array}$ \\
\hline Mood/Mental health & $49(80)$ \\
\hline Location of gyms & $48(78)$ \\
\hline Education level & $35(57)$ \\
\hline Transportation & $27(45)$ \\
\hline Cost of hair maintenance & $22(38)$ \\
\hline Scalp perspiration & $18(30)$ \\
\hline \multicolumn{2}{|c|}{$\begin{array}{l}\text { Discussing hair maintenance strategies with AA women may } \\
\text { help to increase their frequency of physical } \\
\text { activity/exercise. }\end{array}$} \\
\hline Agree & $19(31)$ \\
\hline Somewhat agree & $18(29)$ \\
\hline
\end{tabular}

Continued
Table 1. Continued

\begin{tabular}{lc}
\hline $\begin{array}{l}\text { Question and Response Category } \\
(\text { Total N =62) }\end{array}$ & Response, N (\%) \\
\hline Neutral & $19(31)$ \\
Somewhat disagree & $4(6)$ \\
Disagree & $2(3)$ \\
I feel comfortable discussing haircare maintenance strategies \\
$\quad$ with AA females. \\
Agree & $14(23)$ \\
Somewhat agree & $7(11)$ \\
Neutral & $4(6)$ \\
Somewhat disagree & $12(19)$ \\
Disagree & $24(40)$ \\
\hline
\end{tabular}

NP, Nurse Practitioner. PGY, postgraduate year; AA, African American.

August 2011, then US Surgeon General Regina Benjamin, an AA woman, called attention to the problem, "Oftentimes you get women saying, 'I cannot exercise today because I do not want to sweat my hair back or get my hair wet"' ${ }^{10}$ Researchers have noted that there should be a strategic focus placed on identifying patients who find hair maintenance a barrier to exercise. ${ }^{6}$ However, although concerns about hair maintenance could be a potential point of intervention when primary care providers promote exercise to their AA female patients, to our knowledge there are no studies that consider primary care provider perceptions of the management and maintenance of AA female hair. The purpose of this study was to address this gap by identifying primary care provider thoughts, attitudes, beliefs, and knowledge regarding the maintenance of AA female hair as a barrier to increased physical activity.

\section{Methods}

The study setting was a department of family medicine with 8 ambulatory clinics within a large Midwestern academic medical center (AMC). A recruitment e-mail was sent to the department clinician e-mail listserv (151 unique e-mail addresses) that included a link to the survey instrument. The survey elicited clinician thoughts, attitudes, beliefs, and knowledge as it relates to AA hair maintenance and physical activity via Likert, multiple choice, and yes/no questions (see Table 1 for survey questions and answer categories). The final question was open-ended. This study protocol was approved by the institutional review board affiliated with the AMC. 


\section{Results}

A total of 62 clinicians completed the survey ( $41 \%$ response rate). Table 1 presents respondent demographics and a distribution of answers to survey questions. Respondents were identified as nurse practitioners, physician's assistants, and family medicine residents and attendings. There was ethnic diversity among respondents, with $30 \%$ identifying as nonwhite. A total of $95 \%$ of respondents often/sometimes engage in discussions with AA females regarding physical activity; however, $76 \%$ of respondents have never included hairstyling or maintenance assessment in that discussion. From a predetermined list of barriers to increased physical activity, the most frequently selected factors included location/accessibility of a gym, $\mathrm{mood} / \mathrm{men}$ tal health, and transportation. The least frequently selected barriers to increased physical activity included scalp perspiration and cost of hair maintenance.

Nearly $60 \%$ of clinicians believed discussing hair maintenance strategies would be beneficial and possibly help to increase physical activity habits in AA female populations; however, only $34 \%$ of providers noted that they were comfortable or relatively comfortable discussing this topic. Fifty respondents answered the open-ended final question. The majority reported feeling uneducated, unaware, or unfamiliar. One respondent stated, "I know how important it is in the AA community and do not want to upset anyone." Another respondent stated that they were not comfortable with this topic because of "previous episodes of asking about hair to AA females that have resulted in them being insulted."

\section{Discussion}

Overall, the study results indicate clinicians place a value on the health and wellness of patients, and particularly AA female patients, when it comes to discussions of physical activity and exercise. However, the majority of clinicians in this study reported that they do not feel comfortable discussing haircare or hairstyle maintenance with their AA female patients, and furthermore, there was little knowledge of haircare practices as a potential barrier to exercise. The scope of medicine in modern day family practice is multicultural, cross-cultural, and personalized. The patient-clinician discussions regarding physical activity and barriers should re- flect this reality. Our study supports the need to incorporate this cultural competency into continuing medical education opportunities and medical education curriculums.

This study is subject to the external validity threat of a small, single-site case study. In addition, the number of respondents was too small for statistical analysis of responses across physician demographic categories. However, the ethnic diversity of our physician sample and the patients they serve is a strength and supports the external validity of our findings. Given that these providers were not aware or comfortable with AA hair maintenance as a barrier to physical activity, it is reasonable to assume that the majority of primary care providers are not better informed. In addition, $80 \%$ of respondents answered the open-ended question. This is evidence of the interest and novelty of this topic and highlights the need for further study in this area.

The benefits of physician education on this topic are similar to other cultural competency training and could yield improvements in health care provider knowledge, attitudes, and skills and increased patient satisfaction. ${ }^{11,12}$ Furthermore, faculty modeling of cultural competency behavior to learners, that is, medical students and residents, will begin to address knowledge gaps and cultural chasms at an earlier academic level. ${ }^{13}$ Incorporating this knowledge during motivational interviewing will, in theory, begin to reveal barriers to exercise among AA patients and is an important step toward building trust and rapport with patients.

Future studies are needed to develop a continuing medical education curriculum on hair maintenance as a barrier to physical activity, which should be developed in consultation with members of the AA female community, and to test the efficacy of this curriculum. Subsequent studies regarding the efficacy of interventions such as low-maintenance hair styling practices and motivational interviewing may give insight to evidence-based strategies for helping AA females increase their physical activity. ${ }^{14,15}$ Provider education has the potential to improve the physician-patient relationship, which could have a lasting impact on the long-term health outcomes of AA females.

The authors would like to thank the providers who gave their time to respond to our survey and Dr. Faraz Ahmad for his early encouragement as an advisor. 
To see this article online, please go to: bttp://jabfm.org/content/ 32/6/944.full.

\section{References}

1. National Center for Health Statistics. Health, United States, 2011: with special feature on socioeconomic status and health. Hyattsville MD: National Center for Health Statistics; 2012.

2. Railey MT. Parameters of obesity in African-American women. J Natl Med Assoc 2000;92:481-4.

3. Hair BY, Hayes S, Tse CK, Bell MB, Olshan AF. Racial differences in physical activity among breast cancer survivors: implications for breast cancer care. Cancer 2014;120:2174-82.

4. Huebschmann AG, Campbell LJ, Brown CS, Dunn AL. "My hair or my health:" overcoming barriers to physical activity in African American women with a focus on hairstyle-related factors. Women Health 2016;56:428-47.

5. Boyington JE, Carter-Edwards L, Piehl M, Hutson J, Langdon D, McManus S. Cultural attitudes toward weight, diet, and physical activity among overweight African American girls. Prev Chronic Dis 2008;5:A36.

6. Versey HS. Centering perspectives on Black women, hair politics, and physical activity. Am J Public Health 2014;104:810-5.

7. Ahn CS, Suchonwanit P, Foy CG, Smith P, McMichael AJ. Hair and scalp care in African American women who exercise. JAMA Dermatol 2016;152: 579-80.

8. Hall RR, Francis S, Whitt-Glover M, Loftin-Bell K, Swett K, McMichael AJ. Hair care practices as a barrier to physical activity in African American women. JAMA Dermatol 2013;149:310-14.

9. Gathers RC, Mahan MG. African American women, hair care, and health barriers. J Clin Aesthet Dermatol 2014;7:26-9.

10. O'Connor A. Surgeon general calls for health over hair. Available from: https://well.blogs.nytimes.com/ 2011/08/25/surgeon-general-calls-for-health-overhair/? mtrref $=$ www.google.com \& gwh $=3853 \mathrm{E} 4239$ DB915903C61DBB626E2720B\&gwt= pay\&asset Type $=$ REGIWALL. Published 20111. Accessed August 25, 2011.

11. Govere L, Govere EM. How effective is cultural competence training of healthcare providers on improving patient satisfaction of minority groups? A systematic review of literature. Worldviews Evid Based Nurs 2016;13:402-10.

12. Beach MC, Price EG, Gary TL, et al. Cultural competency: a systematic review of health care provider educational interventions. Med Care 2005;43: 356.

13. Rollins LK, Bradley EB, Hayden GF, Corbett EC, Jr., Heim SW, Reynolds PP. Responding to a changing nation: are faculty prepared for cross-cultural conversations and care? Fam Med 2013;45:728-31.

14. Williams WM, Alleyne R, Henley AT. The root of physical inactivity Among African-American women: identifying exercise friendly hairstyles. J Natl Black Nurses Assoc 2017;28:26-31.

15. Joseph RP, Coe K, Ainsworth BE, Hooker SP, Mathis L, Keller C. Hair as a barrier to physical activity among African American women: a qualitative exploration. Front Public Health 2018;5:367. 